\title{
Repair of giant paraesophageal hernias routinely produces improvement in respiratory function
}

\author{
Philip W. Carrott, MD, ${ }^{\mathrm{a}}$ Jean Hong, ARNP, ${ }^{\mathrm{a}}$ MadhanKumar Kuppusamy, MD, ${ }^{\mathrm{a}}$ Steven Kirtland, MD, ${ }^{\mathrm{b}}$ \\ Richard P. Koehler, MD, FACS, a and Donald E. Low, MD, FACS, FRCS(C) ${ }^{\mathrm{a}}$
}

Objective: Assessment of the clinical impact of giant paraesophageal hernias have historically focused on
upper gastrointestinal symptoms. This study assesses the effect of paraesophageal hernia repair on respiratory
function.

Methods: All patients undergoing repair of giant paraesophageal hernia were prospectively entered into a database approved by the institutional review board. Patients had symptoms documented preoperatively, including dyspnea. Pulmonary function tests (PFTs) were done preoperatively and repeated a median of 106 days after repair (range, 16-660 days).

Results: Preoperative and postoperative PFTs were obtained in 120 unselected patients treated for paraesophageal hernia between 2000 and 2010. Patients' median age was 74 years (range, $45-91$ years), 74 (62\%) were female, and median body mass index was 28.0 (range, 16.8-46.6). Median length of stay was 4 days (range, 3-10 days), and perioperative mortality was zero. Hernias were classified as type II in $3(3 \%)$ patients, III in $92(77 \%)$, and IV in $25(21 \%)$. Percent of intrathoracic stomach was assigned from preoperative contrast studies and grouped as less than $50 \%(\mathrm{n}=6 ; 5 \%), 50 \%$ to $74 \%(\mathrm{n}=35 ; 29 \%), 75 \%$ to $99 \%(\mathrm{n}=29 ; 24 \%)$, and $100 \%$ $(\mathrm{n}=50 ; 42 \%)$. Preoperative symptoms included heartburn $71(59 \%)$, early satiety $65(54 \%)$, dyspnea 63 $(52 \%)$, chest pain $48(40 \%)$, dysphagia $56(47 \%)$, regurgitation $47(39 \%)$, and anemia $44(37 \%)$. PFTs significantly improved after paraesophageal hernia repair (mean volume change, percent reference change): forced vital capacity $+0.30 \mathrm{~L},+10.3 \%$ pred; $\mathrm{FEV}_{1}+0.23 \mathrm{~L},+10.4 \%$ pred (all $P<.001$ ); diffusion capacity of the lung for carbon monoxide $+0.58 \mathrm{~mL} \cdot \mathrm{mm} \mathrm{Hg}^{-1} \cdot \mathrm{min}^{-1}(P=.004)$, and $+2.9 \%$ pred $(P=.002)$. Greater improvements were documented in older patients with significant subjective respiratory symptoms and higher percent of intrathoracic stomach $(P<.01)$.

Conclusions: Paraesophageal hernia has a significant effect on respiratory function, which is largely underappreciated. This study demonstrates that these repairs can be done safely and supports routine consideration for elective repair; older patients with borderline respiratory function may achieve substantial improvements in their respiratory status and quality of life. (J Thorac Cardiovasc Surg 2012;143:398-404)

Earn CME credits at

http://cme.ctsnetjournals.org

Dyspnea is known to complicate paraesophageal hiatus hernias, although most symptom assessments concentrate on upper gastrointestinal issues, particularly reflux symptoms. Giant paraesophageal hernias may occupy a large, variable space in the chest and affect respiratory function. In theory,

From the Sections of General Thoracic Surgery ${ }^{\mathrm{a}}$ and Pulmonary Medicine, ${ }^{\mathrm{b}}$ Virginia Mason Medical Center, Seattle, Wash.

Disclosures: Authors have nothing to disclose with regard to commercial support.

Read at the 37th Annual Meeting of The Western Thoracic Surgical Association, Colorado Springs, Colorado, June 22-25, 2011.

Received for publication June 21, 2011; revisions received Sept 14, 2011; accepted for publication Oct 20, 2011; available ahead of print Nov 21, 2011.

Address for reprints: Donald E. Low, FACS, FRCS(C), Section of General Thoracic Surgery, Virginia Mason Medical Center, 1100 Ninth Ave, C6-SUR, Seattle, WA 98111 (E-mail: gtsdel@vmmc.org).

$0022-5223 / \$ 36.00$

Copyright (C) 2012 by The American Association for Thoracic Surgery doi: $10.1016 /$ j.jtcvs.2011.10.025 reducing the herniated stomach to the abdomen and restoring normal diaphragmatic anatomy should improve respiratory function. We aim to document changes in respiratory function after paraesophageal hernia repair in a diverse group of patients and highlight those patient and anatomic characteristics that are associated with significant improvements in respiratory reserve.

The relationship between giant paraesophageal hernia and dyspnea has been noted as early as the $1960 \mathrm{~s} .{ }^{1-3}$ However, only 5 of 13 recent case series examining symptoms associated with paraesophageal hernias assessed patients for dyspnea preoperatively. ${ }^{4-16}$ The reported incidence of preoperative dyspnea ranged from $7 \%$ to $32 \%$, with 3 of these 5 series indicating an incidence of $30 \%$ or higher. ${ }^{5,9-11,14}$ Patients with paraesophageal hiatal hernias tend to be elderly and often have other comorbidities that could contribute to dyspnea. The majority of physicians do not relate chronic respiratory symptoms to the presence of paraesophageal hernias.

Recognizing the potential for improvement in pulmonary function after paraesophageal hernia repair is important; 


\section{Abbreviations and Acronyms \\ DLCO $=$ diffusion capacity of the lung for carbon monoxide \\ $\mathrm{FEV}_{1}=$ forced expiratory volume in 1 second \\ GEJ = gastroesophageal junction \\ $\%$ pred $=$ percent predicted \\ PFT = pulmonary function test}

older patients with pulmonary comorbidities may be deemed ineligible for surgical treatment when they may benefit the most from repair. We previously documented significant improvements in respiratory function after paraesophageal hernia repair in 45 selected patients, $84 \%$ of whom had dyspnea preoperatively. ${ }^{17}$ This group included 2 patients requiring oxygen therapy who were able to discontinue it after repair. Since that time, preoperative and postoperative pulmonary function testing has been part of our routine workup for patients undergoing elective paraesophageal hernia repair. We aim to update this series in an unselected population with giant paraesophageal hernia from the past 11 years.

\section{METHODS}

All patients $(n=270)$ between 2000 and 2010 undergoing elective repair of giant paraesophageal hernias were enrolled in a prospective institutional review board-approved database and reviewed. Information regarding patient demographics, symptoms, investigations, and treatment were recorded in the database. The criterion for obtaining pulmonary function tests (PFTs) was the presence of a giant (type II, III, or IV) paraesophageal hernia. These hernias also routinely involve greater than $50 \%$ of the stomach on upper gastrointestinal study. Only patients who completed both preoperative and postoperative PFTs were included in analysis $(\mathrm{n}=120)$. Fifty-three additional patients completed preoperative PFTs but would not return for a postoperative study. The most common reason for patient noncompliance with follow-up was related to satisfaction with the symptomatic outcome, leaving them disinclined to return for additional objective testing. The majority of these patients $(70 \%)$ were from greater than 50 miles away.

Patient symptoms, signs, lifestyle modifications, comorbidities, and objective studies were all recorded in the database. All patients included in the study had a preoperative upper gastrointestinal barium swallow study and $114(95 \%)$ underwent manometry, with a solid-state, high-resolution system placed over endoscopically positioned wire (Sierra Scientific Instruments Inc, Los Angeles, Calif). Two patients had a preoperative gastric emptying study and 10 underwent 24-hour $\mathrm{pH}$ study. Postoperative follow-up was standardized and patients were routinely assessed for subjective improvement in symptoms, including respiratory function, and follow-up PFTs were routinely requested at a 3-month office visit.

The Hill repair was used for $99 \%$ of patients treated in this series. The procedure involves anchoring the gastroesophageal junction (GEJ) in the abdomen by pexy to the preaortic fascia or crural repair with 5 sutures that also re-form the flap valve of the GEJ. ${ }^{8,9}$ The Hill repair does not routinely require the use of a Collis gastroplasty inasmuch as the anchoring sutures allow the esophagus to be under some tension after repair, which other methods of repair (eg, Nissen fundoplication) do not allow.

Descriptive statistics were used to assess continuous variables with range or standard deviation, and categorical variables were reported as frequencies and associated percentages. Between-group comparisons of categorical outcomes were performed using Fisher's exact test and the KruskalWallis test as appropriate to the distribution of the data, with $P$ values denoting levels of statistical significance. The Student paired $t$ test was used to assess the significance between preoperative and postoperative PFT results, with $95 \%$ confidence intervals given to show significance.

In addition, a nominal regression was used to compare patients as grouped by their improvement in forced expiratory volume in 1 second $\left(\mathrm{FEV}_{1}\right)$ after surgery. Three groups were formed as minimal improvement (percent predicted [\%pred] change in $\mathrm{FEV}_{1}<5 \%$ ), moderate improvement (5\%-15\% improvement in \%pred $\mathrm{FEV}_{1}$ ), and greatest improvement $\left(>15 \%\right.$ pred $\left.\mathrm{FEV}_{1}\right)$. These groups were chosen on the basis of having roughly equal groups for comparison. Nominal regression compared each of the more improved patients with the minimal improvement group. Statistical analyses were performed using SPSS (version 18) software package (SPSS Inc, Chicago, Ill).

\section{RESULTS}

Preoperative and postoperative PFTs were obtained in 120 of 270 patients undergoing paraesophageal hernia repair at our institution between 2000 and 2010. For this subgroup of 120 patients, median age was 74 years (range, 45-91 years), $74(62 \%)$ patients were female, and median body mass index was 28.0 (range, 16.8-46.6). Patients in the group that completed 2 PFT examinations were more likely to have a larger percent of intrathoracic stomach (median, $80 \%$ vs $75 \% ; P=.003$ ) and were older (median age, 74.5 vs 66.5 years; $P<.001$ ) than the remainder of the group $(\mathrm{n}=150)$. Preoperative dyspnea was also more common in the group that completed 2 PFTs $(63 / 120$ [53\%] vs $67 / 150$ [45\%]; $P=.09)$. Cases were elective in $116(97 \%)$ and urgent in $4(3 \%)$; an open Hill repair was performed in 119 $(99 \%)$ patients. Major comorbidities included obesity (body mass index > 30) in $43(39 \%)$; cardiac, $42(35 \%)$; pulmonary, 35 (29\%); renal, 14 (12\%); and diabetes, 7 $(5 \%)$. Median length of stay was 4 days (range, 3-10 days), and perioperative mortality was zero. Complications occurred in $39(33 \%)$ patients and included arrhythmias in 6 , prolonged nausea delaying discharge in 4 , pneumonia in 3 , ileus in 3 , urinary retention in 2 , wound infection in 2 , delirium in 2 , pulmonary embolus in 1 , and stroke in 1 . Preoperative symptoms and issues pertinent to the paraesophageal hernia were assessed in detail, with a median of 4 symptoms per patient (range, 1-8). Symptoms, signs, and lifestyle modifications in the study group are seen in Table 1.

Paraesophageal hernia was type II in $3(3 \%)$ patients, type III in $92(77 \%)$, and type IV in $25(21 \%)$. Percent of intrathoracic stomach was independently assessed by gastrointestinal radiologists from preoperative contrast studies and grouped as follows: less than $50 \%(n=6 ; 5 \%), 50 \%$ to $74 \%(\mathrm{n}=35 ; 29 \%), 75 \%$ to $99 \%(\mathrm{n}=29 ; 24 \%)$, and $100 \%(\mathrm{n}=50 ; 42 \%)$. For the entire population of $120 \mathrm{pa}-$ tients, differences in PFTs demonstrated significant improvement after paraesophageal hernia repair, as shown in Table 2. These PFTs included forced vital capacity; $\mathrm{FEV}_{1}$; forced expiratory flow between $25 \%$ and $75 \%$ of 
TABLE 1. Symptoms and issues associated with paraesophageal hernia in the patient population $(n=120)$

\begin{tabular}{lc}
\hline \multicolumn{1}{c}{$\begin{array}{c}\text { Symptom, sign or lifestyle } \\
\text { modification }\end{array}$} & n (\%) \\
\hline Heartburn & $71(59 \%)$ \\
Early satiety & $65(54 \%)$ \\
$\quad$ Decreased meal size & $27(23 \%)$ \\
Dyspnea & $63(53 \%)$ \\
Dysphagia & $56(47 \%)$ \\
Chest pain & $48(40 \%)$ \\
Regurgitation & $47(39 \%)$ \\
Avoid nocturnal meal & $5(4 \%)$ \\
Avoid certain foods & $12(10 \%)$ \\
Head of bed elevation & $9(8 \%)$ \\
Anemia & $44(37 \%)$ \\
Cough & $19(16 \%)$ \\
No symptoms & $0(0 \%)$ \\
\hline
\end{tabular}

vital capacity, as corrected for forced vital capacity; vital capacity; and diffusion capacity of the lung for carbon monoxide (DLCO). Levels of improvements in these commonly used parameters were then analyzed with regard to the objective and subjective patient characteristics of sex, age, type of paraesophageal hernia, percent of intrathoracic stomach, preoperative dyspnea, presence of pulmonary comorbidity, preoperative $\mathrm{FEV}_{1}$, and postoperative dyspnea improvement, as shown in Tables 3 and 4.

Male and female patients differed only with respect to mean $\mathrm{FEV}_{1}$ volume change $(P=.047)$ and percent of intrathoracic stomach, with the male patients demonstrating a higher average amount of herniated stomach $(P=.002)$. Percent of intrathoracic stomach at presentation significantly increased with advanced age. Table 3 shows PFT changes and percent of intrathoracic stomach when assessed according to sex, age group, type of hernia, and percent of intrathoracic stomach. Significant improvements in spirometric values, but not DLCO, were documented in patients with higher percent of intrathoracic stomach $(P<.01)$.

In Table 4, changes in spirometric values and DLCO are shown with respect to whether dyspnea was a presenting symptom and the presence of pulmonary comorbidities. Of patients with dyspnea, only $22(35 \%)$ had documented pulmonary comorbidities $(P=.13)$. Changes in objective parameters were also measured according to level of pulmonary impairment, as expressed by \%pred of preoperative $\mathrm{FEV}_{1}$. Changes in objective parameters were also assessed according to whether the patient noted a subjective improvement postoperatively. All objective parameters, spirometric and diffusion capacity, were significantly improved for the patients noting subjective improvement.

Patients who had more compromised preoperative studies, defined as a presenting $\mathrm{FEV}_{1}$ of $75 \%$ or less of predicted, had larger hernias, as expressed by percentage of intrathoracic stomach $(87 \%$ vs $74 \% ; P<.001)$. They also demonstrated a significant improvement in vital capacity $(P=.012)$ and $\operatorname{DLCO}(P=.004)$ after repair. Additionally, in the 43 patients with reduced $\mathrm{FEV}_{1}$ preoperatively, 36 $(83 \%)$ demonstrated a greater degree of subjective respiratory improvement after operation $(P<.001)$ as compared with $53 \%$ of patients with near-normal preoperative $\mathrm{FEV}_{1}$. Those patients who noted subjective improvement after repair routinely demonstrated significant improvements in PFTs, both spirometric and DLCO $(P<.01$; Table 4).

Improvement in objective parameters was not entirely dependent on the presence of dyspnea preoperatively. Of the 63 patients who had preoperative dyspnea, 47 (75\%) reported disappearance of symptoms postoperatively $(P=.01)$. Additionally, $30(53 \%)$ of the 57 patients not describing dyspnea preoperatively reported a noticeable improvement in their respiratory status postoperatively, and $40(70 \%)$ of 57 had greater than $5 \%$ pred improvement in $\mathrm{FEV}_{1}$ after repair.

Nominal regression was conducted with patients grouped into 3 categories according to the level of postoperative percent of reference $\mathrm{FEV}_{1}$ improvement: less than $+5 \%$ pred change; from $+5 \%$ to $+15 \%$ pred change; and greater than or equal to $+15 \%$ pred. Covariables considered were age, American Society of Anesthesiology class, body mass index, sex, pulmonary comorbidities, preoperative $\mathrm{FEV}_{1}$, percent of intrathoracic stomach group, and type of paraesophageal hernia. Only percent of intrathoracic stomach was found to be significant in accounting for the level of improvements between groups $(P=.001)$. When the 41 $(34 \%)$ patients showing minimal or no objective improvement after the procedure $\left(<5 \%\right.$ pred in $\left.\mathrm{FEV}_{1}\right)$ are compared

TABLE 2. Spirometric and diffusion capacity changes from preoperative to postoperative PFTs for the entire population

\begin{tabular}{lccc}
\hline \multicolumn{1}{c}{ PFT } & Raw change $(\mathbf{9 5} \% \mathbf{C I})$ & $\begin{array}{c}\text { Percent predicted change } \\
\text { (95\% CI) }\end{array}$ & \multicolumn{1}{c}{$\boldsymbol{P}$ value } \\
\hline FVC & $+0.303 \mathrm{~L}(0.242-0.363)$ & $+10.3(8.2-12.4)$ & $<.001$ \\
FEV & $+0.236 \mathrm{~L}(0.189-0.283)$ & $+10.4(8.3-12.5)$ & $<.001$ \\
IsoFEF25-75 & $+0.249 \mathrm{~L}(0.151-0.319)$ & $\mathrm{NR}$ & $<.001$ \\
VC & $+0.286 \mathrm{~L}(0.226-0.347)$ & $+9.9(7.8-12.0)$ & $<.001$ \\
DLCO $\left(\mathrm{mL} \cdot \mathrm{mm} \mathrm{Hg}^{-1} \cdot \mathrm{min}^{-1}\right)$ & $+0.582(0.185-0.978)$ & $+2.86(1.1-4.6)$ & $.004, .002$ \\
\hline$P F T, \mathrm{P})$ &
\end{tabular}

$P F T$, Pulmonary function test; $C I$, confidence intervals; $F V C$, forced vital capacity; $F E V_{l}$, forced expiratory volume in 1 second; IsoFEF25-75, forced expiratory flow between $25 \%$ and $75 \%$ of vital capacity, as corrected for FVC; $V C$, vital capacity; $D L C O$, diffusion capacity of the lung for carbon monoxide; $N R$, not reported. 
TABLE 3. Average changes from preoperative to postoperative PFTs by patient demographics and paraesophageal hernia anatomy

\begin{tabular}{|c|c|c|c|c|c|c|c|}
\hline & $\mathbf{n}$ & $\begin{array}{c}\text { Average } \\
\% \text { ITS }\end{array}$ & $\begin{array}{c}\text { FVC difference } \\
(\% \text { pred })\end{array}$ & $\begin{array}{c}\text { FEV }_{1} \text { difference } \\
(\% \text { pred })\end{array}$ & $\begin{array}{c}\text { IsoFEF25-75 } \\
\text { difference }\end{array}$ & $\begin{array}{c}\text { VC difference } \\
(\% \text { pred })\end{array}$ & $\begin{array}{c}\text { DLCO } \\
\left(\mathrm{mL} \cdot \mathrm{mm} \mathrm{Hg}^{-1} \cdot \mathbf{m i n}^{-1}\right) \\
\text { difference }(\% \text { pred })\end{array}$ \\
\hline Female & 74 & $74 \%$ & $+0.267 \mathrm{~L}(+11.2)$ & $+0.195 \mathbf{L}(+11.0)$ & $+0.194 \mathrm{~L}$ & $+0.247 \mathrm{~L}(+10.4)$ & $+0.305(+1.8)$ \\
\hline Male & 46 & $86 \%$ & $+0.360 \mathrm{~L}(+8.9)$ & $+\mathbf{0 . 3 0 2} \mathbf{L}(+9.4)$ & $+0.339 \mathrm{~L}$ & $+0.348 \mathrm{~L}(+9.0)$ & $+0.976(+4.4)$ \\
\hline \multicolumn{8}{|l|}{ Age (y) } \\
\hline$<60$ & 15 & $71 \%$ & $+0.323 \mathrm{~L}(+7.9)$ & $+0.255 \mathrm{~L}(+8.1)$ & $+0.314 \mathrm{~L}$ & $+0.317 \mathrm{~L}(+7.8)$ & $+0.636(+2.1)$ \\
\hline $60-69$ & 30 & $75 \%$ & $+0.266 \mathrm{~L}(+8.1)$ & $+0.193 \mathrm{~L}(+7.0)$ & $+0.175 \mathrm{~L}$ & $+0.255 \mathrm{~L}(+7.9)$ & $+0.617(+2.9)$ \\
\hline $70-79$ & 45 & $77 \%$ & $+0.281 \mathrm{~L}(+9.6)$ & $+0.232 \mathrm{~L}(+10.4)$ & $+0.229 \mathrm{~L}$ & $+0.263 \mathrm{~L}(+9.0)$ & $+0.363(+1.3)$ \\
\hline$>80$ & 30 & $\mathbf{8 8} \%$ & $+0.361 \mathrm{~L}(+15.1)$ & $+0.275 \mathrm{~L}(+15.3)$ & +0.322 & $+0.340 \mathrm{~L}(+14.7)$ & $+0.879(+6.1)$ \\
\hline Type II & 3 & $\mathbf{5 8} \%$ & $+0.463 \mathrm{~L}(+14.7)$ & $+0.353 \mathrm{~L}(+14.3)$ & $+0.413 \mathrm{~L}$ & $+0.460 \mathrm{~L}(+14.7)$ & $-0.867(-3.3)$ \\
\hline Type III & 92 & $\mathbf{7 4} \%$ & $+0.268 \mathrm{~L}(+8.9)$ & $+0.209 \mathrm{~L}(+9.1)$ & $+0.207 \mathrm{~L}$ & $+0.242 \mathrm{~L}(+8.2)$ & $+0.505(+2.7)$ \\
\hline Type IV & 25 & $100 \%$ & $+0.409 \mathrm{~L}(+15.2)$ & $+0.319 \mathrm{~L}(+15.0)$ & $+0.386 \mathrm{~L}$ & $+0.428 \mathrm{~L}(+\mathbf{1 5 . 6})$ & $+1.05(+4.3)$ \\
\hline$<50 \%$ ITS & 6 & $38 \%$ & $+0.130 \mathrm{~L}(+4.7)$ & $+0.083 L(+3.8)$ & $-0.075 \mathrm{~L}$ & $+0.088 \mathrm{~L}(+3.0)$ & $+0.360(0)$ \\
\hline $50 \%-74 \%$ ITS & 35 & $\mathbf{5 6} \%$ & $+0.163 \mathrm{~L}(+6.0)$ & $+0.099 \mathrm{~L}(+5.1)$ & $+0.034 \mathrm{~L}$ & $+0.148 \mathrm{~L}(+5.6)$ & $+0.313 \mathrm{~L}(+1.7)$ \\
\hline $75 \%-99 \%$ ITS & 29 & $78 \%$ & $+0.279 \mathrm{~L}(+9.1)$ & $+0.214 \mathrm{~L}(+9.1)$ & $+0.262 \mathrm{~L}$ & $+0.245 \mathrm{~L}(+8.4)$ & $+0.445(+3.2)$ \\
\hline $100 \%$ ITS & 50 & $100 \%$ & $+0.435 \mathrm{~L}(+14.9)$ & +0.362 L $(+15.9)$ & $+0.432 L$ & $+0.434 \mathrm{~L}(+14.9)$ & $+0.873(+3.8)$ \\
\hline
\end{tabular}

Average values for raw difference and percent of predicted were calculated separately. Significant differences are shown in boldface $(P<.05)$. $P F T$, Pulmonary function test; $\% I T S$, percent of intrathoracic stomach; $F V C$, forced vital capacity; $F E V_{l}$, forced expiratory volume in 1 second; $I$ soFEF $25-75$, forced expiratory flow between $25 \%$ and $75 \%$ of vital capacity, as corrected for FVC; $V C$, vital capacity; $D L C O$, diffusion capacity of the lung for carbon monoxide.

with the $35(29 \%)$ patients with most pronounced $(\geq 15 \%$ pred in $\mathrm{FEV}_{1}$ ) objective improvement after repair, patients showing the greatest improvements were older (70.7 vs 74.3 years), had greater percent of intrathoracic stomach $(68 \%$ vs $87 \%)$, and demonstrated a greater degree of subjective improvement in respiratory function ( $46 \%$ vs $71 \%$ ).

\section{DISCUSSION}

The optimal timing of repair of paraesophageal hiatal hernias continues to be controversial. ${ }^{18,19}$ In addition, previous reports have suggested that a significant portion of patients with giant paraesophageal hernias are asymptomatic. ${ }^{19,20}$ Symptom assessments typically focus on issues associated with reflux or dysphagia, although we have found that when patients are questioned closely about other signs or symptoms, they often will report additional issues such as early satiety (as manifested by pain or bloating with eating), dyspnea, or a history of anemia. Our initial experience with a subset of patients, many of whom were dyspneic before paraesophageal hernia repair, prompted us to conduct investigations into a wider population. ${ }^{17}$ Not every patient experienced an improvement in dyspnea after repair. However, the majority of patients who had dyspnea preoperatively did notice a degree of improvement, and the difference was measurable with pulmonary function parameters. Pertinently, even patients without a preoperative perception of dyspnea can demonstrate subjective improvement $(53 \%)$ and objective improvement $(70 \%)$ after repair.

Intuitively, reduction of the paraesophageal hernia and returning the stomach and other organs to the abdomen should improve respiratory mechanics because normal anatomy is restored. Initial reports investigating the effects of paraesophageal hernia on pulmonary function were not

TABLE 4. Average changes from preoperative to postoperative PFTs by respiratory symptoms, comorbidities, and preoperative respiratory function $\left(\mathbf{F E V}_{\mathbf{1}}\right)$

\begin{tabular}{|c|c|c|c|c|c|c|c|}
\hline & $\mathbf{n}$ & $\begin{array}{c}\text { Average } \\
\% \text { ITS }\end{array}$ & $\begin{array}{c}\text { FVC difference } \\
(\% \text { pred })\end{array}$ & $\begin{array}{c}\text { FEV }_{1} \text { difference } \\
(\% \text { pred }) \\
\end{array}$ & $\begin{array}{c}\text { IsoFEF25-75 } \\
\text { difference } \\
\end{array}$ & $\begin{array}{c}\text { VC difference } \\
(\% \text { pred })\end{array}$ & $\begin{array}{c}\text { DLCO } \\
\left(\mathrm{mL} \cdot \mathrm{mm} \mathrm{Hg}^{-1} \cdot \mathbf{m i n}^{-1}\right) \\
\text { difference }(\% \text { pred }) \\
\end{array}$ \\
\hline Preop dyspnea & 63 & $83 \%$ & $+0.325 \mathrm{~L}(+11.5)$ & $+0.272 \mathrm{~L}(12.2)$ & $+0.326 \mathrm{~L}$ & $+0.313 \mathrm{~L}(+11.2)$ & $+0.755(+3.2)$ \\
\hline No dyspnea preop & 57 & $\mathbf{7 4} \%$ & $+0.278 \mathrm{~L}(+9.1)$ & $+0.195 \mathrm{~L}(+8.5)$ & $+0.165 \mathrm{~L}$ & $+0.257 \mathrm{~L}(+8.4)$ & $+0.398(+2.5)$ \\
\hline Pulmonary comorbidity & 35 & $80 \%$ & $+0.346 \mathrm{~L}(+13.0)$ & $+0.269 \mathrm{~L}(+12.8)$ & $+0.283 \mathrm{~L}$ & $+0.313 \mathrm{~L}(+12.3)$ & $+0.926(+4.6)$ \\
\hline No pulmonary comorbidity & 85 & $78 \%$ & $+0.285 \mathrm{~L}(+9.3)$ & $+0.222 \mathrm{~L}(+9.5)$ & $+0.236 \mathrm{~L}$ & $+0.275 \mathrm{~L}(+9.0)$ & $+0.455(+2.2)$ \\
\hline $\mathrm{FEV}_{1} \leq 75$ & 43 & $87 \%$ & $+0.386 \mathrm{~L}(+13.9)$ & $+0.297 \mathrm{~L}(+13.4)$ & $+0.349 \mathrm{~L}$ & $+0.391 L(+13.8)$ & $+\mathbf{1 . 2 3 4}(+5.5)$ \\
\hline $\mathrm{FEV}_{1}>75$ & 77 & $74 \%$ & $+0.256 \mathrm{~L}(+8.4)$ & $+0.201 \mathrm{~L}(+8.8)$ & $+0.194 \mathrm{~L}$ & $+0.229(+7.8)$ & $+\mathbf{0 . 2 3 2}(+\mathbf{1 . 5})$ \\
\hline Minimal subjective change in RF & 43 & $73 \%$ & $+0.197 \mathrm{~L}(+6.8)$ & $+0.136 L(+6.2)$ & $+0.091 L$ & $+0.168 L(+6.0)$ & $-0.268(-0.3)$ \\
\hline Notable subjective change in RF & 77 & $82 \%$ & $+0.362 L(+12.3)$ & $+0.291 L(+12.7)$ & $+0.338 L$ & $+0.353 L(+12.1)$ & $+1.074(+4.7)$ \\
\hline
\end{tabular}

Average values for raw difference and percent of predicted were calculated separately. Significant differences are shown in boldface $(P<.05)$. $P F T$, Pulmonary function test; $F E V_{l}$, forced expiratory volume in 1 second; $\% I T S$, percent of intrathoracic stomach; $F V C$, forced vital capacity; IsoFEF $25-75$, forced expiratory flow between $25 \%$ and $75 \%$ of vital capacity, as corrected for FVC; $V C$, vital capacity; $D L C O$, diffusion capacity of the lung for carbon monoxide; $R F$, respiratory function. 
able to reliably define how the hernia affects respiration. ${ }^{1-3}$ Anecdotally, we see a large proportion of paraesophageal hernia patients who will notice some degree of breathlessness after meals or with certain postural maneuvers, such as on bending over to tie one's shoes. Activities that increase intra-abdominal pressure will cause acute symptoms, which can worsen as the hernia grows over time. This is supported by our findings that objective testing shows the greatest improvement in hernias that encompassed $100 \%$ of the stomach.

The exact physiologic impact that the paraesophageal hernia exerts on respiratory function is likely from a combination of factors. As the hernia enlarges, thoracic volume is reduced. There are also reports in the literature in which cardiac function was improved by repair of hiatal hernia. ${ }^{21}$ Diaphragm dysfunction likely also plays a role, perhaps owing to paradoxical movement of the stomach during respiration. As the negative pressure in the chest draws air in, it may also draw the stomach and other abdominal viscera into the chest, thus reducing the force and volume available for respiration. This could be thought of as an internal flail segment of the chest. Depending on the size of the stomach and the amount ingested during a meal, the volume displaced by intrathoracic stomach may be quite dramatic in patients with larger hernias. The changes in objective measurements of pulmonary function shown in Table 2 support a mixed effect of the hernia on pulmonary function inasmuch as there are improvements in both restrictive and obstructive parameters, as well as diffusion capacity. We are currently conducting a study using plethysmography with the spirometric and diffusion capacity testing on these patients that may give us more information on the cause of pulmonary dysfunction.

What do these findings mean with respect to the management of individual patients with giant paraesophageal hernia? The most pronounced improvements in respiratory function occurred in patients with the largest hernias. Interestingly, it is the oldest portion of the population who typically has the largest hernias and will benefit most from repair. These patients are precisely the group that is most likely to be turned down for repair owing to their age or comorbid conditions. These conditions can include impaired preoperative pulmonary function or reduced pulmonary reserve, which now clearly has significant potential for improvement after repair. Although there was no statistical association with preoperative PFTs and the presence of dyspnea or pulmonary comorbidity, we noted a greater tendency for improvement in PFT values in patients with preoperative pulmonary symptoms and comorbidities. It is equally clear that patients who do not have the perception of dyspnea preoperatively demonstrate both objective and subjective improvement after repair.

The size of the hernia, reflected by the percent of intrathoracic stomach, was without question the most important single factor in predicting postoperative improvement in PFTs. This estimation was made by the radiologist on viewing preoperative upper gastrointestinal contrast studies. The most pronounced improvement was noted in the oldest patients (age $>80$ ), patients with the largest hernias, and those with the most impaired preoperative respiratory function.

Percent of intrathoracic stomach also was the only predictor for improvement in regression analysis when level of postoperative improvement in $\mathrm{FEV}_{1}$ was analyzed using nominal regression analysis in which a wide variety of presenting factors were identified. Accordingly, age, body mass index, pulmonary comorbidity, sex, paraesophageal hernia type, and American Society of Anesthesiology class did not independently contribute to the degree of improvement in $\mathrm{FEV}_{1}$ after repair.

This study does have limitations in being a single-center experience, largely by a single surgeon. In addition, we were not able to have all patients return for repeat PFTs. However, this population is unselected on the basis of symptoms and was not found to significantly differ from the remainder of the group on this point. Despite this, those patients completing 2 PFTs were older and had larger percent of intrathoracic stomach, indicating that they may have been selected subjectively, perhaps on the basis of poorer baseline health status. Although there is undoubtedly a bias in getting PFTs in patients who had larger hernias and were older, the numbers are relatively large in that $120 \mathrm{pa}-$ tients are included in our study population. This population is powerful enough to show significant differences in the spectrum of pulmonary function parameters. In addition, the method of repair is not widely used but has been shown in previous reports to have reliable results. ${ }^{8,9}$ Improvement in pulmonary function, however, should be seen with all other methods of repair, provided that the rate of recurrence is acceptably low.

This study has implications for many patients with paraesophageal hiatal hernias. The symptoms associated with paraesophageal hernia are wider than most physicians realize, and the potential for improvement of symptoms is also much greater than presently described in the literature. It is widely appreciated that these hernias will continue to grow over time. We believe that patients who have a symptomatic paraesophageal hernia should be given the opportunity to consult with an experienced surgeon, even when the patient has associated comorbidities that might otherwise disqualify them from other major surgery.

\section{CONCLUSIONS}

A significant proportion of patients with giant paraesophageal hernias will report dyspnea. Repair of the hernia will lead to subjective and objective improvement in the majority of patients. The degree of improvement in PFT values is most often associated with elderly patients, large hernias, and the presence of preoperative dyspnea. In 
addition to the potential for improving gastrointestinal symptoms, elective paraesophageal hernia repair should be considered in elderly patients with large hernias, with a reasonable expectation of improvement in pulmonary reserve.

\section{References}

1. Senyk J, Arborelius M Jr, Lilja B, Ohlsson NM. Respiratory function in esophageal hiatus hernia. I. Spirometry, gas distribution, and arterial blood gases. Respiration. 1975;32:93-102.

2. Senyk J, Arborelius M Jr, Lilja B. Respiratory function in esophageal hiatus hernia. II. Regional lung function. Respiration. 1975;32:103-11.

3. Selmonosky CA, Blanc JS, Byrd R. Hiatal hernia and pulmonary function impairment: incidence or coincidence? South Med J. 1980;73:1234-6.

4. Andujar JJ, Papasavas PK, Birdas T, Robke J, Raftopoulos Y, Gagne DJ, et al. Laparoscopic repair of large paraesophageal hernia is associated with a low incidence of recurrence and reoperation. Surg Endosc. 2004;18:444-7.

5. Dallemagne B, Kohnen L, Perretta S, Weerts J, Markiewicz S, Jehaes C. Laparoscopic repair of paraesophageal hernia: long-term follow-up reveals good clinical outcome despite high radiological recurrence rate. Ann Surg. 2011;253:291-6.

6. Furnee EJ, Draaisma WA, Simmermacher RK, Stapper G, Broeders IA. Longterm symptomatic outcome and radiologic assessment of laparoscopic hiatal hernia repair. Am J Surg. 2010;199:695-701.

7. Hashemi M, Peters JH, DeMeester TR, Huprich JE, Quek M, Hagen JA, et al. Laparoscopic repair of large type III hiatal hernia: objective followup reveals high recurrence rate. J Am Coll Surg. 2000;190:553-60.

8. Jobe BA, Aye RW, Deveney CW, Domreis JS, Hill LD. Laparoscopic management of giant type III hiatal hernia and short esophagus. Objective follow-up at three years. J Gastrointest Surg. 2002;6:181-8.

9. Low DE, Unger T. Open repair of paraesophageal hernia: reassessment of subjective and objective outcomes. Ann Thorac Surg. 2005;80:287-94.

10. Maziak DE, Todd TR, Pearson FG. Massive hiatus hernia: evaluation and surgical management. J Thorac Cardiovasc Surg. 1998;115:53-60.

11. Nason KS, Luketich JD, Qureshi I, Keeley S, Trainor S, Awais O, et al. Laparoscopic repair of giant paraesophageal hernia results in long-term patient satisfaction and a durable repair. J Gastrointest Surg. 2008;12:2066-75.

12. Patel HJ, Tan BB, Yee J, Orringer MB, Iannettoni MD. A 25-year experience with open primary transthoracic repair of paraesophageal hiatal hernia. J Thorac Cardiovasc Surg. 2004;127:843-9.

13. Pierre AF, Luketich JD, Fernando HC, Christie NA, Buenaventura PO, Litle VR, et al. Results of laparoscopic repair of giant paraesophageal hernias: 200 consecutive patients. Ann Thorac Surg. 2002;74:1909-15.

14. Rogers ML, Duffy JP, Beggs FD, Salama FD, Knowles KR, Morgan WE. Surgical treatment of para-oesophageal hiatal hernia. Ann R Coll Surg Engl. 2001;83: 394-8.

15. Velanovich V, Karmy-Jones R. Surgical management of paraesophageal hernias: outcome and quality of life analysis. Dig Surg. 2001;18:432-7.

16. Ellis FH Jr, Crozier RE, Shea JA. Paraesophageal hiatus hernia. Arch Surg. 1986; 121:416-20.

17. Low DE, Simchuk EJ. Effect of paraesophageal hernia repair on pulmonary function. Ann Thorac Surg. 2002;74:333-7.

18. Davis SS Jr. Current controversies in paraesophageal hernia repair. Surg Clin North Am. 2008;88:959-78, vi.

19. Stylopoulos N, Gazelle GS, Rattner DW. Paraesophageal hernias: operation or observation? Ann Surg. 2002;236:492-500.

20. Schieman C, Grondin SC. Paraesophageal hernia: clinical presentation, evaluation, and management controversies. Thorac Surg Clin. 2009;19:473-84.

21. Gillinov AM, Rice TW. Prandial atrial fibrillation: off-pump pulmonary vein isolation with hiatal hernia repair. Ann Thorac Surg. 2004;78:1836-8.

\section{Discussion}

Dr Sean C. Grondin (Calgary, Alberta, Canada). I thank the Association for the opportunity to review this paper and I thank Drs Carrott and Low and their coauthors for providing me with the manuscript in a timely fashion for review.
The authors have presented work on a relatively common disease that is pertinent to most practicing thoracic surgeons. Their goal was to address the relationship between paraesophageal hernia, dyspnea, and pulmonary function. I have a few comments and 2 questions.

This was a retrospective observational study with the inherent bias that accompanies this type of review. Only 120 of the total 270 patients were eligible to participate in the study. Although 120 patients is a fair number of participants, it is less than $44 \%$ of the total number of patients in the database. Additionally, the authors reported that a greater percent of patients with dyspnea-53\% versus $45 \%$ - participated in the study, which could imply selection bias. Pulmonary function tests were used to measure overall pulmonary function, and these were done in a fairly short time interval (3 months) after the operation and were not repeated. The authors reported a statistically significant $10 \%$ improvement in pulmonary function, which they concluded in the manuscript improved quality of life of patients.

My first question for the authors is this: You mention that the theory as to why the pulmonary function improved after surgery may be due to the improvement in diaphragmatic function as a result of correcting the diaphragmatic anatomy. Do you think there could be other explanations for this observed improvement in pulmonary function?

Dr Carrott. Thank you, Dr Grondin, for your comments. Let me first address the question regarding the sample size of the study population. You note correctly that only $44 \%$ of our total volume underwent both pre- and postoperative testing. We actually had more than 100 additional preoperative studies, but because of the age of the study population (median age, 74) and in many cases the significant distance traveled for their surgery, many of these elderly patients, when satisfied with their clinical outcome, were disinclined to return for routine 3-month follow-up.

You also mentioned that this is a common disease in your practice as it is in Dr Low's. However, giant paraesophageal hernias are actually rare clinical issues in most surgeons' practices and are not part of any differential diagnosis regarding dyspnea in the practices of primary care doctors or pulmonary specialists. There is also a persistent impression in some quarters that these hernias are asymptomatic. We believe the impact on respiratory function is another reason to consider elective repair in these patients, especially when unexplained dyspnea is a component of their presentation.

With respect to the theory as to why pulmonary function is impaired in the presence of these giant hernias, our manuscript reviews our current theories that it is a combination of factors that is suggested by the improvement we have noted in both restrictive and obstructive measures. However, the size of the hernias and an associated compressive effect on both the lungs and the heart have been postulated previously. We also believe that restoring normal diaphragmatic anatomy and function by closing the hiatus reduces the paradoxic motion of the hernia during respiration. This could also be one of the explanations why dyspnea is often related to certain exertional maneuvers or postural change.

Dr Grondin. Two things you might consider are preoperative computed tomographic scan to look for lung compression, as we do with giant bullae of the lung, and an exercise echocardiogram to tease out whether there may also be a cardiac component contributing to dyspnea in a large hernia. 
Second, going forward, are there any other tests you would use to determine whether the reported improvement in pulmonary function is really clinically relevant, or are we just documenting a change in two numbers but without clinical relevance?

Dr Carrott. I believe that is a very good suggestion and, in fact, it is one of the issues that we considered when we designed our original paraesophageal hernia database. Having computed tomographic scans on all patients might very well give us some additional volumetric information in a standard format; however, we felt that it would be a difficult issue to get through our institutional review board, considering that computed tomographic scans are not usually indicated in these patients and the additional expense and radiation exposure would become issues. However, we have initiated an institutional review board-approved process of obtaining plethysmography assessments on these patients in the pre- and postoperative setting because we believe that the assessment of changes in expiratory reserve volume, total lung capacity, and residual volume may give us additional insights into why these people show respiratory improvement.

Dr Grondin. Quality of life surveys and dyspnea questionnaires that are validated are sometimes useful in evaluating changes in dyspnea and exercise capacity.

In summary, I would like to recognize the hard work that you and your coauthors have invested in the development and completion of this study. In my opinion the study has provided supportive inference that paraesophageal hernia may improve pulmonary function, but I think the results still fall short of providing conclusive evidence at this time. I would caution surgeons against telling patients they will obtain a definitive improvement in dyspnea after giant paraesophageal hernia repair.

Dr Carrott. Once again, Dr Grondin, thank you for your comments. We will remain a little more optimistic regarding our results. This is our second assessment of this question. The first being an examination of a selected population of patients with dyspnea and giant paraesophageal hernias and this, much larger assessment, in an unselected population. In addition to noticing a statistically significant improvement in spirometric values in the entire study population, we have also documented that $75 \%$ of patients with dyspnea preoperatively and more than $50 \%$ of patients with no perception of shortness of breath in the preoperative period will note subjective improvements in their respiratory status after surgical repair. We believe that these results are compelling and should be more widely disseminated, especially with respect to medical physicians treating elderly patients with these giant hernias.

Dr Ross M. Bremner (Phoenix, Ariz). I wish Sean had not just made that last comment because I have long been telling my patients who have their entire stomach in the chest that they are likely to get some improvement in their pulmonary function. Now at least I have some data to show them; at least that they can expect $10 \%$ or $15 \%$ improvement.

I have a couple of questions. One is related to your technique. How much laparoscopy you are using with these patients and are you using the Collis procedure? It seemed as though you never used a Collis in these patients (we similarly are reluctant to use that operation), but there are some large centers in the country that use Collis up to $40 \%$ of the time in patients with these intrathoracic stomachs. Could you comment on that?

Dr Carrott. Thank you, Dr Bremner. We share your feelings regarding improvement in respiratory status and we agree that data are very helpful when reviewing the advantages of repair with both patients and other physicians.

The majority of the operations in this series were performed as open Hill operations. This was our standard practice earlier in the decade and it was the methodology that we used to specifically avoid the necessity of doing a Collis operation in a percentage of these patients. The Hill operation is predicated on firmly anchoring the phrenoesophageal attachments in the abdominal cavity, which makes a Collis operation unnecessary even in patients with relative esophageal shortening. More recently, we have been doing approximately $50 \%$ of our giant hernias laparoscopically, but we are selecting patients who show appropriate movement of their esophagogastric junction on preoperative swallow studies and being particularly careful in patients who have coexistent Barrett's esophagus, esophageal stricture, and a history of severe esophagitis.

Dr Bremner. How about the use of Collis? Is that something you do not use very often?

Dr Carrott. The answer to your question regarding a Collis procedure is we continue to modify our approach on our preoperative perception of esophageal shortening. We believe the risk is significant with the risk factors I just mentioned, specifically Barrett's, esophageal stricture, and esophagitis in association with these giant paraesophageal hernias. We continue to advocate using the Hill operation to avoid the necessity of a Collis procedure.

Dr Bremner. Finally, a lot of these patients have chronic aspiration, which may result from esophageal motility problems because the esophagus cannot work well inasmuch as it is accordionized in the chest, and some may be related to reflux disease. Could you give us an idea how much of the contribution to the improvement in pulmonary function is related to improvement in aspiration? Do you have data with respect to the incidence of cough and how cough improves after these operations?

Dr Carrott. I think your comment highlights something that we mentioned earlier regarding the perception that the improvement in respiratory status is almost certainly multifactorial. Although gastroesophageal reflux disease is not always a presenting problem in patients with these large hernias, it certainly can be and there will be a subsection of that group, especially in the elderly population, that will be at increased risk for nocturnal regurgitation and aspiration issues. We always use an antireflux operation with the repair of these giant hernias and I think it is highly likely that decreasing levels of gastroesophageal reflux disease, regurgitation, and aspiration are factors in the overall improvement we see in these patients.

Dr Bremmer. Thanks and congratulations. Great study.

Dr Carrott. Thank you. 